\title{
OCORRÊNCIA DO MAL-DO-PÉ CAUSADO POR Gaeumannomyces graminis var. graminis, UMA NOVA ENFERMIDADE EM ARROZ NO BRASIL
}

\author{
ANNE S. PRABHU ${ }^{1} \&$ MARTA C. FILIPPI ${ }^{1}$ \\ ${ }^{1}$ Embrapa Arroz e Feijão, Cx. Postal 179, CEP 75375-000, Santo Antônio de Goiás, GO,
}

Fax: (62) 533-2100, e-mail: prabhu@cnpaf.embrapa.br

(Aceito para publicação em 05/04/2002)

Autor para correspondência: Anne Sitarama Prabhu

PRABHU, A.S. \& FILIPPI, M.C. Ocorrência do mal-do-pé causado por Gaeumannomyces graminis var. graminis, uma nova enfermidade em arroz no Brasil. Fitopatologia Brasileira 27:417-419. 2002.

\section{RESUMO}

O mal-do-pé em arroz (Oryza sativa) foi constatado em lavouras de terras altas nos municípios de Unaí (MG), Palmeiras (GO), Itaberaí (GO), Humaitá (AM) e em lavouras irrigadas nos Estados de Goiás, Tocantins e Rio Grande de Sul. O agente causal foi identificado como Gaeumannomyces graminis var. graminis baseado em características morfológicas, culturais e testes de patogenicidade utilizando diferentes isolados brasileiros. O método de inoculação e avaliação da doença em de casa de vegetação foi descrito. Este é o primeiro registro desta enfermidade na cultura do arroz no Brasil.

Palavras-chave adicionais: Oryza sativa, doenças de arroz, patogenicidade, etiologia, resistência varietal.

\section{ABSTRACT
Occurrence of crown sheath rot caused by Gaeumannomyces graminis var. graminis, a new rice disease in Brazil}

Crown sheath rot also known as black sheath rot has been found to occur in upland rice (Oryza sativa) in the municipalities of Unaí (MG), Palmeiras(GO), Itaberaí (GO), Humaitá (AM) and in flooded rice in the States of Goiás, Tocantins and Rio Grande de Sul. The causal agent was identified as
Gaeumannomyces graminis var. graminis based on morphological and cultural characteristics of the fungus as well as pathogenicity tests conducted utilizing different Brazilian isolates. This constitutes the first report of the disease occurrence in rice in Brazil.
A doença do arroz ( Oryza sativa L.) denominada como mal-do-pé causada por Gaeumannomyces graminis (Sacc.) von Arx \& D. Oliver var. graminis foi constatada nos EUA, Japão, Filipinas e Índia (Datnoff et al., 1993). Embora a ocorrência do mal-do-pé, cujo agente causal é o fungo Gaeumannomyces graminis var. tritici, tenha sido relatada desde de 1944, na cultura do trigo (Triticum aestivum L.) no Rio Grande de Sul e Paraná, os danos causados nesta cultura só foram significativos na safra de 1987 (Reis, 1989). Solos com pH 5,5 ou superior associado ao excesso de chuvas durante vários anos foram apontados como fatores que favoreceram a alta incidência do mal-do-pé (Prestes, 1972; Reis et al., 1982, 1983). O agente causal do mal-do-pé afeta diversas gramíneas como Pennisetum spp., Stenotaphrum spp. e Cynadon spp. que podem constituir-se em hospedeiros secundários para a sobrevivência do patógeno em arroz (Walker, 1975; Datnoff et al., 1997).

No ano agrícola de 1997/98, constatou-se pela primeira vez o mal-do-pé em arroz, em lavouras de terras altas com irrigação suplementar, sob pivô central, nos municípios de Unaí (MG), Palmeiras (GO), Itaberaí (GO), Humaitá (AM) e nos campos experimentais da Embrapa Arroz e Feijão em Santo Antônio de Goiás. No ano seguinte, a mesma enfermidade foi encontrada em diversas lavouras de arroz de terras altas, com ou sem irrigação, em arroz inundado nos campos experimentais da Embrapa Arroz e Feijão (Fazenda Palmital), no município de Brazabrantes, no estado de Goiás e em lavouras de arroz inundado no Projeto Rio Formoso e no município de Lagoa da Confusão no estado do Tocantins (Prabhu \& Filippi, 1999; Vaz et al., 2000). Posteriormente, a ocorrência de mesma enfermidade foi constatada em lavouras de arroz irrigado no estado do Rio Grande do Sul. Nas lavouras de arroz afetadas, a doença causou o amadurecimento rápido dos grãos e até morte dos perfilhos, dependendo da época de seu aparecimento durante a fase de crescimento e desenvolvimento da planta. O sintoma característico da doença é uma coloração marrom escura ou preta na bainha, na base do colmo, no primeiro e segundo nós e entre-nós. As raízes das plantas afetadas estavam associadas com o fungo G. graminis var. graminis e apresentavam uma coloração preta resultando, em alguns casos, na morte da planta.

No presente trabalho foram conduzidos estudos relativos à etiologia, patogenicidade do agente causal e resistência varietal à doença na cultura do arroz.

Foram obtidos isolados do patógeno, a partir de colmos de arroz, apresentando sintomas da doença, procedentes de lavouras de Unaí (MG), Paraúna (GO), Humaitá (AM), Brazabantes (GO) e Formoso do Araguaia (TO). Os tecidos 
de partes do colmo e raízes das plantas doentes foram desinfetados com hipoclorito de sódio, transferidos para placas de Petri contendo ágar-água suplementado com sulfato de estreptomicina $(100 \mu \mathrm{g} / \mathrm{l})$. Após três a quatro dias, porções da periferia das colônias foram transferidas para batata-dextroseágar (BDA). Culturas puras do organismo, com característica típica de micélio escuro e denso, foram mantidas em tubos contendo o mesmo meio de cultura.

$\mathrm{O}$ agente causal do mal-do-pé foi identificado como G. graminis var. graminis, com base nos hifopódios lobados e ascas unitunicadas. Os hifopódios produzidos abundantemente no micélio, na superfície do tecido da planta infetada, são achatados, hialinos ou pardos claros e lobados (Figura 1). As macro-hifas são septadas e crescem longitudinalmente sobre as regiões dos colmos e raízes afetadas. Os peritécios são escuros, esféricos formados nas bainhas das plantas e produzidos abundantemente em grãos de milheto autoclavados. As ascas, que contêm oito ascósporos, são alongadas e clavadas, apresentando um anel apical distinto. Os ascósporos são hialinos, filiformes com três a cinco septos (Walker, 1975). Os ascósporos foram liberados quando os peritécios foram transferidos para gotas de água esterilizada. Foram realizados isolamentos monospóricos de ascósporos, os quais foram mantidos em tubos com BDA. O inóculo para os testes de patogenicidade foi multiplicado em meio constituído de grãos de milheto ou de arroz em casca autoclavados em frascos de Erlenmeyer $(500 \mathrm{ml})$ e em placas de Petri contendo palitos de dente mergulhados em ágar-água.

Os testes de patogenicidade foram realizados utilizando-se dois métodos. No primeiro deles, procedeu-se a inoculação das plantas com palitos de dente previamente colonizados pelo micélio. A semeadura do arroz foi feita semanalmente, em vasos com capacidade para $6 \mathrm{~kg}$ de solo adubado com $5 \mathrm{~g}$ de NPK (5-30-15) e $1 \mathrm{~g}$ de sulfato de zinco. Os isolados Gg 001 e Gg 002, provenientes de Humaitá, foram utilizados para a inoculação de plantas da cultivar Maravilha, em diferentes estádios de desenvolvimento. Os tratamentos incluíram seis idades de plantas $(89,96,103,111,118$, e 125 dias após a semeadura) e dois tipos de inoculação com palitos

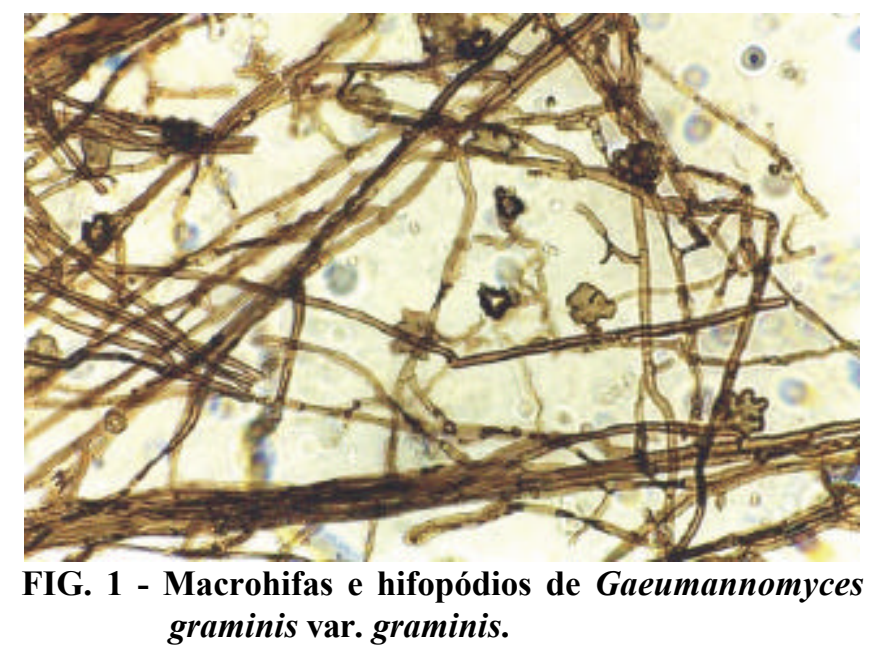

de dente. Em um tratamento os palitos de dente foram inseridos entre a bainha e o colmo, na altura do segundo nó, em três perfilhos de cada uma das três plantas do vaso e, no outro tratamento, os palitos de dente, em numero de três, foram inseridos na base de cada uma das plantas.

Utilizou-se delineamento de blocos casualizados com três repetições, totalizando nove plantas para cada um dos tratamentos. As observações foram feitas 27 dias após a inoculação, avaliando-se a extensão da lesão no colmo e a presença de micélio e peritécio.

No segundo método de inoculação, procedeu-se a infestação da vermiculita, com inóculo multiplicado em grãos de milheto ou grãos de arroz com casca. A vermiculita, autoclavada e mantida em vasos de alumínio com capacidade de $1 \mathrm{~kg}$, foi infestada com inóculo produzido em grãos de milheto ou grãos de arroz na concentração de $5 \%$ (v/v) com três diferentes isolados provenientes de Humaitá (Gg 001) Paraúna (Gg 003) e Unaí (Gg 004). O plantio das duas cultivares de arroz de terras altas, Maravilha e Primavera, foi feito com sementes previamente esterilizadas com $0,1 \%$ hipoclorito de sódio por $20 \mathrm{~min}$. As observações foram feitas 20 dias após a semeadura.

A patogenicidade dos isolados Gg 001 e Gg 002 foi comprovada na cultivar Maravilha. Observaram-se os sintomas típicos da doença em todas as idades das plantas, confirmados pela presença do micélio e de peritécios do patógeno nas bainhas. Não houve diferenças significativas em número de plantas infetadas entre as inoculações feitas com palitos de dente na bainha ou na base da planta. A soca, após a colheita apresentou sintomas semelhantes.

Nos testes de infestação do substrato (vermiculita) foram observados os sintomas da doença, em plântulas com uma e duas folhas, tanto na cultivar Maravilha como na Primavera. Os isolados provenientes de Humaitá, Paraúna e Unaí foram patogênicos às duas cultivares de arroz utilizadas. Tanto o inóculo multiplicado em grãos de milheto como em grãos de arroz com casca apresentaram resultados semelhantes, embora o inóculo proveniente de grãos de milheto tenha apresentado uma infecção mais uniforme das plântulas.

Os testes de resistência varietal foram realizados utilizando 12 genótipos de arroz irrigado de 76 dias de idade, plantados em vasos de alumínio com capacidade para $2 \mathrm{~kg}$ de solo esterilizado, mantendo-se uma planta por vaso. Foram feitas as inoculações com o isolado Gg 002 de G. graminis var. graminis, multiplicado em grãos de milheto autoclavados, colocando-se $5 \mathrm{~g}$ de inóculo na superfície do solo ao redor da base da planta. As plantas inoculadas foram mantidas com alta umidade relativa do ar $(90 \%)$, continuamente por três semanas. $\mathrm{O}$ ensaio foi realizado utilizando o delineamento de blocos ao acaso com quatro repetições. As avaliações foram feitas 24 dias após a inoculação. A extensão da lesão (o comprimento do colmo com lesão marrom e escura, em cm) foi considerada como o parâmetro para avaliação de resistência relativa. Todos os 12 genótipos testados (Figura 2) apresentaram reação de suscetibilidade, não diferindo estatisticamente 


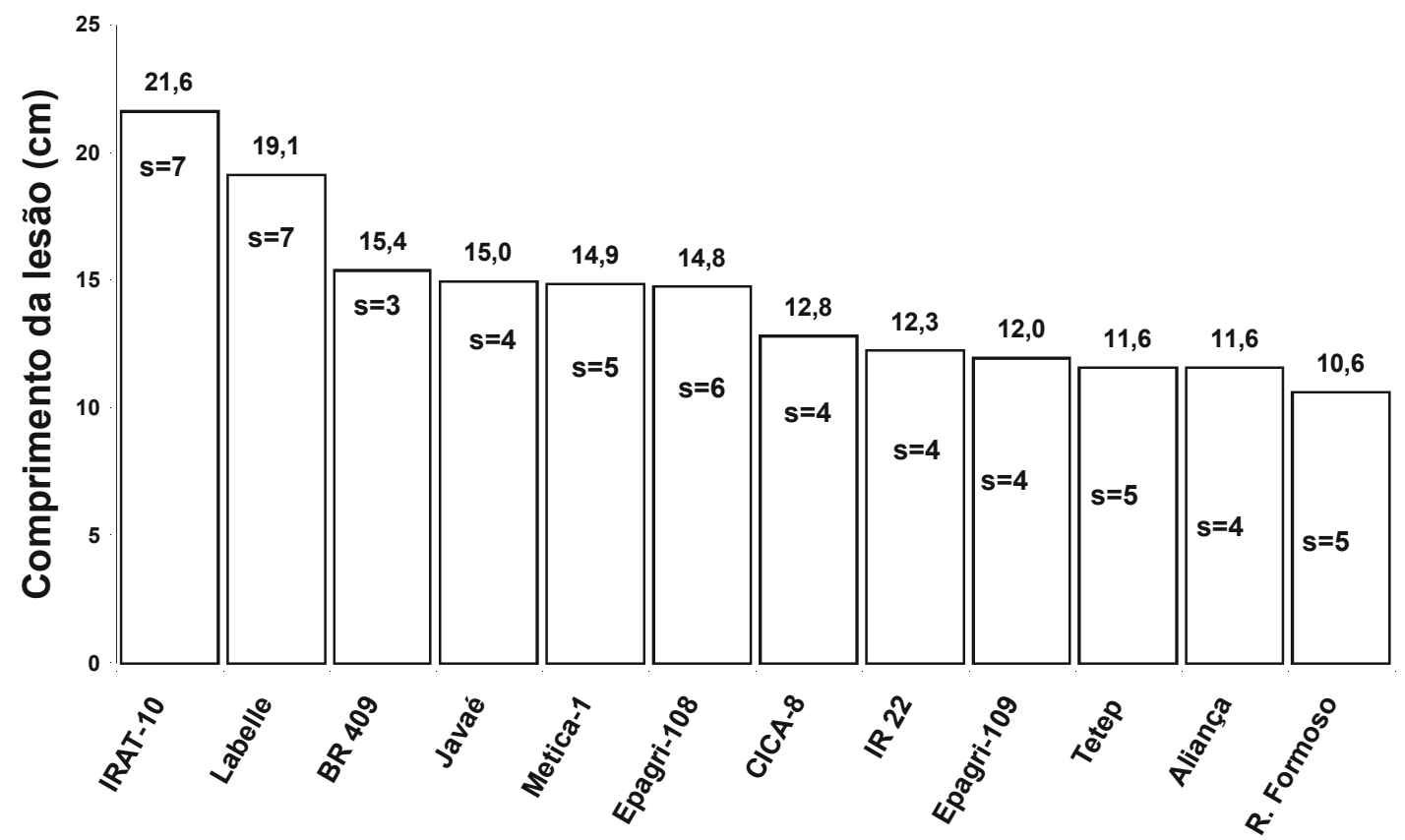

\section{Cultivar}

FIG. 2 - Diferenças varietais de arroz (Oryza sativa) em relação a severidade do mal-do-pé utilizando o isolado Gg 002 de Gaeumannomyces graminis var. graminis, em condições artificiais de inoculação $(s=$ desvio padrão).

entre si $(\mathrm{CV}=21 \%)$, pelo teste de Tukey $(\mathrm{p}=0,05)$. Em algumas cultivares observou-se a morte das folhas novas.

Segundo Walker (1975) os resultados de testes de resistência varietal com este patógeno são variáveis dependendo do meio de cultura e do método de inoculação utilizados. Os resultados do teste em vasos com solo esterilizado e inoculado com isolado do patógeno multiplicado em grãos de milheto mostrou que esta técnica é segura e pode ser utilizada em futuros estudos.

\section{REFERÊNCIAS BIBLIOGRÁFICAS}

DATNOFF, L.E., ELLIOT, M.L. \& KRAUSZ, J.P. Cross pathogenicity of Gaeumannomyces graminis var. graminis from bermudagrass, St. Augustine grass, and rice in Florida and Texas. Plant Disease 81:1127-1131. 1997.

DATNOFF, L.E., ELLIOT, M.L. \& JONES, D.B. Black sheath rot caused by Gaeumannomyces graminis var. graminis on rice in Florida. Plant Disease 77:210. 1993.
PRABHU, A.S. \& FILIPPI, M.C. Ocorrência do mal-do-pé, uma nova enfermidade em arroz, no Brasil. Summa Phytopathologica 25:33-34. 1999. (Resumo).

PRESTES, A.M. Acerca do mal do pé do trigo (Ophiobolus graminis) no Rio Grande do Sul. Revista da Sociedade Brasileira de Fitopatologia 5:169-170. 1972. (Resumo).

REIS, E.M. Doenças do trigo. II. O mal-do-pé. 2.ed. Ciba-Geigy, 1989.

REIS, E.M., COOK, R.J. \& MCNEAL, B.L. Effect of mineral nutrition on take-all of wheat. Phytopathology 72:224-229. 1982.

REIS, E.M., COOK, R.J. \& MCNEAL, B.L. Elevated pH and reduced nutrient availability as factors contributing to takeall of wheat upon soil liming. Phytopathology 73:411-413. 1983.

VAZ, V.J., SANTOS, G.R., BARRETO, R.W., PRABHU, A.S.\& ALVES, M.A.N. Ocorrência de doenças da bainha do colmo em arroz irrigado no Estado do Tocantins. Fitopatologia Brasileira 25:254. 2000. (Resumo)

WALKER, J. Take-all diseases of gramineae: a review of recent work. Review of Plant Pathology 54:113-144. 1975. 